\title{
A Comprehensive Evaluation of Peripheral Analgesic and Antipyretic Activities of Divalent Metal Complexes of Indomethacin
}

\author{
Abhijit Sukul, Sabiha Chowdhury, Saikat Kumar Poddar, \\ Sajal Kumar Saha and S. M. Abdur Rahman
}

Department of Clinical Pharmacy and Pharmacology, Faculty of Pharmacy, University of Dhaka, Dhaka-1000, Bangladesh

(Received: August 01, 2017; Accepted: September 20; Published (web): December 23, 2017)

\begin{abstract}
Comparative peripheral analgesic and antipyretic activities of copper, zinc, cobalt and manganese complexes of indomethacin were studied. Peripheral analgesic effect of the complexes was evaluated by following acetic acid-induced writhing inhibition method in mice whereas antipyretic activity was assessed by Brewer's yeastinduced pyrexia in rat model. At $10-$ and $20-\mathrm{mg} / \mathrm{kg}$ doses, the zinc-indomethacin complex produced significant writhing inhibition $(\mathrm{p}<0.001)$ by $67.35 \%$ and $77.55 \%$ whereas cobalt-indomethacin showed writhing inhibition by $61.22 \%$ and $64.63 \%$ in a dose dependent manner respectively, which were prominent compared to that of standard indomethacin $(61.90 \%$ and $72.27 \%$ inhibition respectively). Moreover, the zinc-indomethacin complex exerted significant antipyretic activity at both $10-$ and $20-\mathrm{mg} / \mathrm{kg}$ dose by reducing body temperature from $100.38^{\circ} \mathrm{F}$ to $97.8^{\circ} \mathrm{F}\left(4^{\text {th }}\right.$ hour $)$ and $100.36^{\circ} \mathrm{F}$ to $98.21^{\circ} \mathrm{F}$ ( $4^{\text {th }}$ hour $)$, respectively that were comparable to standard paracetamol. From this study, it can be said that, with further pharmacological and toxicological profiling of the zinc and cobalt complex of indomethacin, it may pave the way of discovering new drug entity.
\end{abstract}

Key words: Metal-indomethacin complex, pyrexia, writhing, prostaglandin, Brewer's yeast.

\section{INTRODUCTION}

Non-steroidal anti-inflammatory drugs, abbreviated as NSAIDs, have become one of the most widely prescribed and over-the-counter drugs for pain, inflammation, and fever management. Inflammation can occur in any tissue in response to trauma, infection, ischaemia, toxic or autoimmune injury and it plays a role in the recovery from infection. ${ }^{1}$ Some bioactive compounds, namely prostaglandins, are involved in causing inflammation. Prostaglandins are synthesized by an enzyme called prostaglandin synthase, otherwise known as cyclooxygenase (COX). The primary mechanism of action of NSAIDs is the inhibition of this enzyme. In the early 1990s, it was discovered that COX-1 and COX-2 are the two isoforms of COX..$^{2-4}$ Inhibition of

Correspondence to: S. M. Abdur Rahman

Cell: +8801732477343;

E-mail: smarahman@du.ac.bd

Dhaka Univ. J. Pharm. Sci. 16(2): 173-178, 2017 (December)
COX enzymes decreases the production of prostaglandins, resulting in the decrease in inflammation. ${ }^{5,6}$ However, some prostaglandins have their own gastro-protective role, therefore decrease of those prostaglandins can cause gastrointestinal damage. ${ }^{7}$ Beyond inhibiting the synthesis of these prostaglandins, NSAIDs can also cause direct damage to the mucosal surface by disrupting the surface-active phospholipids present on it. ${ }^{8,9}$ Moreover, NSAIDs reduce secretion of bicarbonate and mucous, which can suppress the effectiveness of the juxtamucosal $\mathrm{pH}$ gradient involved in the protection of the mucosal epithelium..$^{10,11}$ The most significant among all of the adverse effects of these drugs include gastrointestinal (GI) ulceration and bleeding. ${ }^{12,13}$ There are also increased risks of cardiovascular events. ${ }^{14,15}$ Though widely used, the ulceration and bleeding caused by these drugs remain a major clinical concern. ${ }^{8,16}$ Researchers are taking 
different approaches to minimize these serious adverse effects of NSAIDs, and several trials have been conducted as well. To minimize the associated adverse effects from the use of NSAIDs, selective COX-2 inhibitors were designed and marketed, which later was found out to cause serious cardiovascular complications including myocardial infarction, heart failure, stroke etc. ${ }^{17}$

Indomethacin is a commonly used NSAID to reduce fever, pain, muscle stiffness and swelling. Like other NSAIDs, it also causes gastrointestinal bleeding which may lead to multifarious complications. ${ }^{18}$ As a matter of fact, the importance of development of NSAIDs with more potency and less damaging gastro-intestinal effect has led to the preparation, characterization, and clinical use of divalent metal complexes of indomethacin. ${ }^{19}$ To the best of our knowledge, the number of investigations on pharmacological properties of different metal complexes of indomethacin is only a few. Therefore, the present study was undertaken to make comparative evaluation of peripheral analgesic and antipyretic effect of indomethacin complexes with cobalt, copper, zinc and manganese.

\section{MATERIALS AND METHODS}

Drugs and materials. The raw indomethacin was obtained from Ningbo-smart Pharmaceuticals, China. Chemicals such as copper sulphate pentahydrate, zinc sulphate heptahydrate, cobalt chloride hexahydrate and manganese sulphate monohydrate were collected from Aristopharma Ltd. and ACI Pharmaceuticals Ltd., Bangladesh.

Solvents and reagents. Dimethyl sulfoxide (DMSO) and sodium bicarbonate were purchased from Merck, Darmstadt, Germany. Tween-80 was procured from Sigma Chemicals, USA, and normal saline was obtained from Opsonin Pharma.

Experimental animals. Swiss-Albino mice, aged 3-4 weeks and Long Evans rats (weighing 100-150 g) of either sex were collected from the International Center for Diarrhoeal Diseases and Research, Bangladesh (ICDDR,B) for the experiment. They were housed in the standard polypropylene cages (30x20x13 cm) and kept under standard environmental conditions (relative humidity $55-60 \%$, room temperature $23 \pm 2^{\circ} \mathrm{C}$ and 12 hours light/dark cycle). ICDDR, B formulated rodent food and water ad libitum was provided to the animals and were kept for at least 7 days in the environment where the experiment took place before use. The design and conductance of all experimental procedures involving animals was accomplished in accordance to ethical guidelines of the FBS, DU (FBS/15/2015) and under the approval by the Institutional Ethical Committee of Faculty of Biological Science, University of Dhaka.

Synthesis of divalent metal complexes of indomethacin. The synthetic protocol was followed according to a previously reported research work by Sukul et al. $2015 .^{20}$ Firstly, $1.0 \mathrm{~g}$ of indomethacin $(0.0028 \mathrm{~mol})$ and $11.2 \mathrm{ml}$ of acetone were mixed in a beaker. In the mean time, $0.235 \mathrm{~g}$ of sodium bicarbonate $(0.0028 \mathrm{~mol})$ was mixed with $11.2 \mathrm{ml}$ of water. The solutions were blended in a beaker. After that, the solutions of $0.333 \mathrm{~g}$ of cobalt chloride hexahydrate $(0.0014 \mathrm{~mol}), 0.223 \mathrm{~g}$ of copper sulphate pentahydrate $(0.0014 \mathrm{~mol}), 0.236 \mathrm{~g}$ of manganese sulphate monohydrate $(0.0014 \mathrm{~mol})$, and $0.226 \mathrm{~g}$ of zinc sulphate heptahydrate $(0.0014 \mathrm{~mol})$ were prepared in $11.2 \mathrm{ml}$ of water, and these solutions were mixed separately with indomethacin and sodium bicarbonate solution slowly by continuous stirring.

Pharmacological evaluation. The synthesized derivatives were subjected to peripheral analgesic and antipyretic activity bioassay.

Peripheral analgesic activity. Peripheral analgesic activity was determined by acetic acid induced writhing inhibition method in mice. ${ }^{21,22}$ Control group was given 2-3 drops of Tween-80 in $0.9 \%$ saline. Indomethacin was provided to the standard group, while test samples were given to all other groups in both high and low doses (10- and 20$\mathrm{mg} / \mathrm{kg}$ of body weight). After 40 minutes, $0.7 \% \mathrm{v} / \mathrm{v}$ acetic acid $(10 \mathrm{ml} / \mathrm{kg})$ was administered intraperitoneally to each of the animals of all the groups as writhing inducer. Five minutes later, the 
number of writhing were counted for each mouse for fifteen minutes. Percentage of inhibition of writhing compared to control group was taken as an index of analgesia and was calculated using the following formula:

Inhibition $(\%)=\left[\left(\mathrm{W}_{\mathrm{c}}-\mathrm{W}_{\mathrm{t}}\right) \times 100\right] / \mathrm{W}_{\mathrm{c}}$

Where $\mathrm{W}_{\mathrm{c}}$ is the average number of writhing reflex in the control group and $\mathrm{W}_{\mathrm{t}}$ is the average number of writhing in the test groups.

Antipyretic activity. Antipyretic activity of metal complexes of indomethacin was studied in rats having fever induced by $15 \%$ Brewer's yeast. ${ }^{23,24}$ It is considered as a useful test for the screening of synthetic drugs for their antipyretic effect. ${ }^{25}$ Before experimentation, the basal rectal temperatures of the animals were measured by using a clinical digital thermometer. Pyrexia was induced by giving $15 \%$ aqueous suspension of Brewer's yeast in distilled water subcutaneously at a dose of $10 \mathrm{ml} / \mathrm{kg}$ body weight in the back of the neck. Control group was given 2-3 drops of Tween-80 in $0.9 \%$ saline. Test samples were given in two different doses $(10 \mathrm{mg} / \mathrm{kg}$ and $20 \mathrm{mg} / \mathrm{kg}$ body weight) to the test groups and paracetamol used as standard drug was given in 100 $\mathrm{mg} / \mathrm{kg}$ body weight to the standard group. The temperatures were recorded at 1-4 hours after the drug treatment.
Statistical analysis. Statistical analyses were done by using the Statistical Package for Social Science version 16.0 software, and statistical differences between groups were analyzed by oneway analysis of variance ANOVA followed by Dunnett's t-test. Data were represented as means \pm SEM and differences were considered statistically significant at $p<0.05$.

\section{RESULTS AND DISCUSSION}

Structure elucidation. The structures of the synthesized metal complexes were analyzed by FTIR, XRD, UV-Vis, AAS, DSC and confirmed by comparison with published value. ${ }^{26,27}$

Peripheral analgesic activity. The percent inhibition of acetic acid induced writhing by metal complexes of indomethacin has been mentioned in table 1 . At the doses of $10-$ and $20-\mathrm{mg} / \mathrm{kg}$ bw, the zinc-indomethacin complex produced significant writhing inhibition $(\mathrm{P}<0.001)$ by $67.35 \%$ and $77.55 \%$ in test animals, respectively which were even higher to that of standard indomethacin $(61.90 \%$ and $72.27 \%$ writhing inhibition respectively at the same dose levels). In addition, copper complex showed moderate peripheral analgesic potency compared to indomethacin $(53.94 \%$ vs $61.90 \%$ at $10 \mathrm{mg} / \mathrm{kg}$ body

Table 1. Peripheral analgesic activity of indomethacin and its metal complexes.

\begin{tabular}{lllll}
\hline Groups & Dose $(\mathrm{mg} / \mathrm{kg}$ bw) & $\begin{array}{l}\text { Number of writhing } \\
(\text { mean } \pm \text { SEM) }\end{array}$ & \% of writhing & \% of inhibition of writhing \\
\hline $\mathrm{Cp}$ & - & $29.4 \pm 2.29$ & 100 & 0 \\
$\mathrm{I} 1$ & 10 & $11.2 \pm 1.32$ & 38.1 & 61.90 \\
$\mathrm{I} 2$ & $7.63 \pm 1.21$ & 27.73 & 72.27 \\
$\mathrm{ICu} 1$ & 10 & $13.54 \pm 1.52$ & 46.06 & $53.94^{*}$ \\
$\mathrm{ICu} 2$ & 20 & $10.08 \pm 1.11$ & 34.28 & $65.72^{* *}$ \\
$\mathrm{IZn} 1$ & 10 & $9.60 \pm 1.03$ & 32.65 & $67.35^{* * *}$ \\
$\mathrm{IZn} 2$ & 20 & $6.60 \pm 2.04$ & 22.45 & $77.55^{* * *}$ \\
$\mathrm{ICo} 1$ & 10 & $11.40 \pm 1.51$ & 38.78 & $61.22^{* *}$ \\
$\mathrm{ICo} 2$ & 20 & $10.40 \pm 1.75$ & 35.37 & $64.63 * *$ \\
$\mathrm{IMn} 1$ & 10 & $12.20 \pm 1.02$ & 43.54 & $56.46^{*}$ \\
$\mathrm{IMn} 2$ & 20 & $10.60 \pm 1.81$ & 36.05 & $63.95^{* *}$ \\
\hline
\end{tabular}

All values expressed as the mean \pm SEM. Significant at ${ }^{* * *} \mathrm{p}<0.001,{ }^{*}{ }^{*} \mathrm{p}<0.01,{ }^{*} \mathrm{p}<0.05$ compared to control group. I= indomethacin; $\mathrm{ICu}=$ indomethacin-copper; $\mathrm{IZn}=$ indomethacin-zinc; $\mathrm{ICo}=$ indomethacin-cobalt; $\mathrm{IMn}=$ indomethacinmanganese. 
Table 2. Antipyretic activity of metal complexes of indomethacin at a dose of 10- bw and 20-mg/kg bw on Brewer's yeast induced fever in mice.

\begin{tabular}{|c|c|c|c|c|c|c|c|}
\hline \multirow[t]{2}{*}{ Group } & \multirow{2}{*}{ 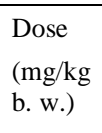 } & \multirow{2}{*}{$\begin{array}{l}\text { Initial } \\
\text { temp. } \\
\left({ }^{\circ} \mathrm{F}\right)\end{array}$} & \multicolumn{5}{|c|}{ Rectal temperature in ${ }^{\circ} \mathrm{F}$ after 18 hours of yeast injection } \\
\hline & & & 0 hour & 1 hour & 2 hour & 3 hour & 4 hour \\
\hline Control & - & $98.5 \pm 0.46$ & $100.37 \pm 0.61$ & $100.43 \pm 0.38$ & $100.85 \pm 0.21$ & $100.72 \pm 0.48$ & $100.68 \pm 0.25$ \\
\hline Paracetamol & 100 & $98.56 \pm 0.36$ & $100.33 \pm 0.29$ & $99.70 \pm 0.21 * *$ & $99.10 \pm 0.16^{* * *}$ & $98.85 \pm 0.06^{* * *}$ & $98.40 \pm 0.07 * * *$ \\
\hline I1 & 10 & $98.5 \pm 0.32$ & $100.37 \pm 0.89$ & $100.10 \pm 0.34$ & $99.73 \pm 0.42$ & $99.25 \pm 0.31$ & $99.80 \pm 0.28$ \\
\hline $\mathrm{I} 2$ & 20 & $98.48 \pm 0.20$ & $100.38 \pm 0.28$ & $99.66 \pm 0.25$ & $99.40 \pm 0.24$ & $98.87 \pm 0.39^{* *}$ & $98.71 \pm 0.47 * *$ \\
\hline $\mathrm{ICu} 1$ & 10 & $98.60 \pm 0.22$ & $100.34 \pm 0.28$ & $99.73 \pm 0.08$ & $99.23 \pm 0.11$ & $98.90 \pm 0.17 * *$ & $98.45 \pm 0.34 * *$ \\
\hline $\mathrm{ICu} 2$ & 20 & $98.58 \pm 0.32$ & $100.36 \pm 0.11$ & $99.58 \pm 0.16$ & $99.34 \pm 0.15$ & $98.77 \pm 0.23$ & $98.65 \pm 0.26^{* *}$ \\
\hline $\mathrm{IZn} 1$ & 10 & $98.53 \pm 0.23$ & $100.38 \pm 0.14$ & $99.63 \pm 0.10^{* * *}$ & $99.05 \pm 0.25 * * *$ & $98.53 \pm 0.29 * * *$ & $97.80 \pm 0.27 * * *$ \\
\hline $\mathrm{IZn} 2$ & 20 & $98.73 \pm 0.13$ & $100.36 \pm 0.09$ & $99.39 \pm 0.28 * * *$ & $98.97 \pm 0.24 * * *$ & $98.55 \pm 0.28 * * *$ & $98.21 \pm 0.39 * * *$ \\
\hline ICo1 & 10 & $98.50 \pm 0.25$ & $100.34 \pm 0.55$ & $99.79 \pm 0.06$ & $99.35 \pm 0.21$ & $98.95 \pm 0.19^{* *}$ & $98.71 \pm 0.25^{* *}$ \\
\hline $\mathrm{ICo} 2$ & 20 & $98.75 \pm 0.22$ & $100.40 \pm 0.09$ & $99.75 \pm 0.08$ & $99.67 \pm 0.23$ & $98.90 \pm 0.31^{* *}$ & $98.74 \pm 0.27 * *$ \\
\hline IMn1 & 10 & $98.65 \pm 0.20$ & $100.36 \pm 0.42$ & $99.70 \pm 0.10$ & $99.28 \pm 0.32 * *$ & $98.88 \pm 0.31 * *$ & $98.50 \pm 0.31 * * *$ \\
\hline IMn2 & 20 & $98.55 \pm 0.29$ & $100.38 \pm 0.52$ & $99.71 \pm 0.13$ & $99.60 \pm 0.34$ & $98.98 \pm 0.38 * *$ & $98.71 \pm 0.27 * *$ \\
\hline
\end{tabular}

All values expressed as the mean \pm SEM. Significant at $* * * \mathrm{p}<0.001,{ }^{* *} \mathrm{p}<0.01,{ }^{*} \mathrm{p}<0.05$ compared to control group. I= indomethacin; $\mathrm{ICu}=$ indomethacin-copper; $\mathrm{IZn}=$ indomethacin-zinc; $\mathrm{ICo}=$ indomethacin-cobalt; $\mathrm{IMn}=$ indomethacin-manganese .

weight and $65.72 \%$ vs $72.27 \%$ at $20 \mathrm{mg} / \mathrm{kg}$ body weight). Similar trend of reduction of analgesic effect were also observed for the manganese complex. Although cobalt complex exhibited comparable analgesic efficacy to indomethacin at $10 \mathrm{mg} / \mathrm{kg}$ body weight (61.22\% vs $61.90 \%)$, it showed lesser effect at $20 \mathrm{mg} / \mathrm{kg}$ body weight ( $64.63 \%$ vs $72.27 \%$ ).

Acetic acid-induced abdominal constrictions are useful experimental tools in the testing of new analgesic drugs. ${ }^{28}$ All the indomethacin-metal complexes reduced the number of abdominal muscle contractions effectively, and among them zincindomethacin complex showed most significant antinociceptive activity, compared to the standard. This pain paradigm is widely used for the assessment of peripheral analgesic activity. ${ }^{29}$ The abdominal injection of acetic acid in mice has been attributed to the localized inflammatory response as a result of free arachidonic acid release from tissue phospholipids via cyclooxygenase (COX), and producing prostaglandin specifically PGE2 and PGF2 $\alpha$. The level of lipoxygenase products may also increase in peritoneal fluids. ${ }^{30,31}$ These prostaglandin and lipoxygenase products cause inflammation and pain by increasing capillary permeability. ${ }^{29}$ Significant inhibition of acetic acid-induced abdominal constrictions by indomethacin metal complexes strongly suggests that the mechanism of analgesic actions of metal complexes are linked to the inhibition of cyclooxygenase and lipoxygenase in the peripheral tissues, thereby reducing PGE2 and PGF2 $\alpha$ synthesis.

Antipyretic activity. Following administration of Brewer's yeast suspension, the effect of standard and test samples on rectal temperature of mice at a dose of $10 \mathrm{mg} / \mathrm{kg}$ and $20 \mathrm{mg} / \mathrm{kg}$ bw were observed (Table 2). The zinc complex of indomethacin showed statistically significant $(\mathrm{P}<0.001)$ antipyretic activity up to 4 hours compared to standard paracetamol in both doses (Table 2). At $10 \mathrm{mg} / \mathrm{kg}$, the zinc complex reduced temperature from $100.38{ }^{\circ} \mathrm{F}$ to $98.53{ }^{\circ} \mathrm{F}$ in 3rd hour $(P<0.001)$ and to $97.8^{\circ} \mathrm{F}(P<0.001)$ in 4 th hour. Similarly, at $20 \mathrm{mg} / \mathrm{kg}$ body weight zinc complex significantly dropped the temperature from $100.36{ }^{\circ} \mathrm{F}$ to $98.55^{\circ} \mathrm{F}$ in 3 rd hour $(P<0.001)$ and to $98.21^{\circ} \mathrm{F}(P<0.001)$ in 4 th hour. Antipyretic activity was found to be more prominent at the dose of 20 $\mathrm{mg} / \mathrm{kg}$ body weight than at the dose of $10 \mathrm{mg} / \mathrm{kg}$ 
body weight. Other complexes of indomethacin also showed antipyretic activity but were not notable when compared to paracetamol.

It is known that most of the anti-inflammatory analgesic drugs also possess antipyretic activity. Subcutaneous injection of Brewer's yeast induces pyrexia by increasing the synthesis of prostaglandin E2 (PGE2) ${ }^{33,26}$ In response to pyrogens, the level of PGE2 rises and it is considered as central mediator for fever. ${ }^{34}$ Furthermore, it can be said that the inhibition of prostaglandin synthesis within the hypothalamus by blocking the cyclooxygenase enzyme activity could be the possible mechanism of antipyretic action as that of paracetamol. ${ }^{35}$

\section{CONCLUSION}

The analgesic and antipyretic effects of the indomethacin-metal complexes provide the initial evidence for further toxicological studies that might pave the way for discovery of a lead for new metalNSAID complexes to treat inflammation and fever with less adverse complications.

\section{ACKNOWLEDGEMENTS}

The authors would like to acknowledge Aristopharma Ltd. and ACI Pharmaceuticals Ltd, Bangladesh for providing raw materials to conduct this research work.

\section{CONFLICT OF INTEREST}

The authors of this study have no conflicting interests that bias the work of this study.

\section{REFERENCES}

1. Nathan, C. and Ding, A. 2010. Nonresolving inflammation. Cell 140, 871-882.

2. Dennis, E. A., Cao, J., Hsu, Y.-H., Magrioti, V. and Kokotos, G. 2011. Phospholipase A2 enzymes: physical structure, biological function, disease implication, chemical inhibition, and therapeutic intervention. Chem. Rev. 111, 6130-6185.

3. Nomura, D. K., Morrison, B. E., Blankman, J. L., Long, J. Z., Kinsey, S. G., Marcondes, M. C. G., Ward, A. M., Hahn, Y.K., Lichtman, A. H., Conti, B., and Cravatt, B. F. 2011. Endocannabinoid hydrolysis generates brain prostaglandins that promote neuroinflammation. Sci. 334, 809-813.
4. Wallace, J. L., Syer, S., Denou, E., Palma, G. D., Vong, L., McKnight, W., Jury, J., Bolla, M., Bercik, P., Collins, S., Verdu, E. and Ongini, E. 2011. Proton pump inhibitors exacerbate NSAID-induced small intestinal injury by inducing dysbiosis. Gastroenterology 141, 1314-1322, 1322. e1-5.

5. Ghosh, N., Chaki, R., Mandal, V., and Mandal, S. C. 2010. COX-2 as a target for cancer chemotherapy. Pharmacol. Rep. PR. 62, 233-244.

6. Sinha, M., Gautam, L., Shukla, P. K., Kaur, P., Sharma, S. and Singh, T. P. 2013. Current perspectives in NSAIDinduced gastropathy. Mediators Inflamm. 13.

7. Singla, P., Bardoloi, A. and Parkash, A. A. 2010. Metabolic effects of obesity: A review. World J. Diabetes 1, 76-88.

8. Blackler, R. W., Gemici, B., Manko, A. and Wallace, J. L. 2014. NSAID-gastroenteropathy: new aspects of pathogenesis and prevention. Curr. Opin. Pharmacol. 19, 11-16.

9. Cryer, B., Bhatt, D.L., Lanza, F.L., Dong, J., Lichtenberger, L.M. and Marathi, U. K. 2011. Low-dose aspirin-induced ulceration is attenuated by aspirin-phosphatidylcholine: a randomized clinical trial. Am. J. Gastroenterol. 106, 272-277.

10. McGuckin, M. A., Lindén, S. K., Sutton, P. and Florin, T. H. 2011. Mucin dynamics and enteric pathogens. Nat. Rev. Microbiol. 9, 265-278.

11. Niv, Y. and Boltin, D. 2012. Secreted and membrane-bound mucins and idiopathic peptic ulcer disease. Digestion $\mathbf{8 6}, 258$ 263.

12. Wallace, J. L. 2013. Mechanisms, prevention and clinical implications of nonsteroidal anti-inflammatory drugenteropathy. World J. Gastroenterol. 19, 1861.

13. Wallace, J.L. 2013. Polypharmacy of osteoarthritis: The perfect intestinal storm. Dig. Dis. Sci. 58, 3088-3093.

14. Meek, I. L., van de Laar, M. A. F. J. and Vonkeman, H. E. 2010. Non-steroidal anti-inflammatory drugs: An overview of cardiovascular risks. Pharma. 3, 2146-2162.

15. Olsen, A.-M.S., Fosbøl, E.L., Lindhardsen, J., Folke, F., Charlot, M., Selmer, C., Lamberts, M., Olesen, J. B., Køber, L., Hansen, P.R., Pedersen, C.T. and Gislason, G.H. 2011. Duration of treatment with nonsteroidal anti-inflammatory drugs and impact on risk of death and recurrent myocardial infarction in patients with prior myocardial infarction: A nationwide cohort study. Circulation 123, 2226-2235.

16. Scarpignato, C. and Hunt, R.H. 2010. Nonsteroidal antiinflammatory drug-related injury to the gastrointestinal tract: clinical picture, pathogenesis, and prevention. Gastroenterol. Clin. North Am. 39, 433-464.

17. Reiss, A.B., Anwar, F., Chan, E.S.L., and Anwar, K. 2009. Disruption of cholesterol efflux by coxib medications and inflammatory processes: link to increased cardiovascular risk. J. Investig. Med. Off. Publ. Am. Fed. Clin. Res. 57, 695-702. 
18. Nakajima, A., Fukui, T., Takahashi, Y., Kishimoto, M., Yamashina, M., Nakayama, S., Sakaguchi, Y., Yoshida, K., Uchida, K., Nishio, A., and Yodoi, J. 2012. Attenuation of indomethacin-induced gastric mucosal injury by prophylactic administration of sake yeast-derived thioredoxin. $J$. Gastroenterol. 47, 978-987.

19. Santini, C., Pellei, M., Gandin, V., Porchia, M., Tisato, F. and Marzano, C. 2014. Advances in copper complexes as anticancer agents. Chem. Rev. 114, 815-862.

20. Sukul, A., Das, S. C., Saha, S. K. and Rahman, S. A. 2015. Screening of analgesic, antimicrobial, cytotoxic and antioxidant activities of metal complexes of indomethacin. Dhaka Univ. J. Pharm. Sci. 13, 175-180.

21. Holzer, P. 2011. Transient receptor potential (TRP) channels as drug targets for diseases of the digestive system. Pharmacol. Ther. 131, 142-170.

22. Park, S.-H., Sim, Y.-B., Lee, J.-K., Kim, S.M., Kang, Y.J., Jung, J.S. and Suh, H.W. 2011. The analgesic effects and mechanisms of orally administered eugenol. Arch. Pharm. Res. 34, 501-507.

23. Abbah, J., Amos, S., Chindo, B., Ngazal, I., Vongtau, H. O., Adzu, B., Farida, T., Odutola, A.A., Wambebe, C. and Gamaniel, K.S. 2010. Pharmacological evidence favouring the use of Nauclea latifolia in malaria ethnopharmacy: effects against nociception, inflammation, and pyrexia in rats and mice. J. Ethnopharmacol. 127, 85-90.

24. Kumar, V. S., Rajmane, A. R., Adil, M., Kandhare, A. D., Ghosh, P. and Bodhankar, S. L. 2014. Naringin ameliorates acetic acid induced colitis through modulation of endogenous oxido-nitrosative balance and DNA damage in rats. $J$. Biomed. Res. 28, 132-145.

25. Khan, H., Saeed, M., Gilani, A.-U.-H., Khan, M. A., Dar, A. and Khan, I. 2010. The antinociceptive activity of Polygonatum verticillatum rhizomes in pain models. $J$. Ethnopharmacol. 127, 521-527.

26. Sukul, A., Poddar, S.K., Saha, S.K. and Das, S.C. 2016. Synthesis and characterization of cobalt and manganese complexes of indomethacin and comparative study of local analgesic, anti-inflammatory, and anti-ulcerogenic properties. Russ. J. Gen. Chem. 86, 1935-1943.

27. Sukul, A., Poddar, S.K., Haque, S., Saha, S.C., Das, S.C., Mahmud, Z.A. and Rahman, S.M.A. 2016. Synthesis, characterization and comparison of local analgesic, antiinflammatory, anti-ulcerogenic activity of copper and zinc complexes of indomethacin. Anti-Inflamm. Anti-Allergy Agents Med. Chem. 15, 221-233.
28. Dina, T. A., Rahman, M. A., Ahmed, N. U. and Uddin, M. N. 2010. Analgesic and anti-inflammatory properties of Argyreia argentea methanol extract in animal model. J. Taibah Univ. Sci.. 3, 1-7.

29. Uddin, G., Rauf, A., Siddiqui, B.S., Muhammad, N., Khan, A. and Shah, S.U.A. 2014. Anti-nociceptive, antiinflammatory and sedative activities of the extracts and chemical constituents of Diospyros lotus L. Phytomedicine 21, 954-959.

30. Muhammad, N., Saeed, M., Khan, H. and Haq, I. 2013. Evaluation of n-hexane extract of Viola betonicifolia for its neuropharmacological properties. J. Nat. Med. 67, 1-8.

31. Scoditti, E., Calabriso, N., Massaro, M., Pellegrino, M., Storelli, C., Martines, G., Caterina, R. D. and Carluccio, M.A, 2012. Mediterranean diet polyphenols reduce inflammatory angiogenesis through MMP-9 and COX-2 inhibition in human vascular endothelial cells: a potentially protective mechanism in atherosclerotic vascular disease and cancer. Arch. Biochem. Biophys. 527, 81-89.

32. Sukul, A., Haque, S., Poddar, S.K., Hossain, M. S., Niloy, K. K. and Saha, S.K. 2017. Comparative physicochemical, antiinflammatory and analgesic activity assay of synthesized chromium and nickel complexes of indomethacin. Cogent Chemistry 3, 1302312.

33. Mathew, M., Xavier, K.A.M., Mathew, S., Asha, K.K. and Kumar, K.A. 2012. Effect of rhizophora root extracts on wound healing and yeast-induced pyrexia in rats. Fish Technol. 49, 161-166.

34. Sehic, E., Székely, M., Ungar, A. L., Oladehin, A. and Blatteis, C. M. 1996. Hypothalamic prostaglandin E2 during lipopolysaccharide-induced fever in guinea pigs. Brain Res. Bull. 39, 391-399.

35. Mazumder, M.M.U., Sukul, A. and Saha, S.K. 2016, Analgesic activities of synthesized divalent metal complexes of tolfenamic acid. Dhaka Univ. J. Pharm. Sci. 15, 89-96. 